\title{
Ossification of the posterior longitudinal ligament: a clinico-radiological study of 74 cases
}

\author{
TADAO NOSE, TAIHEI EGASHIRA, TAKAO ENOMOTO, YUTAKA MAKI \\ From the Department of Neurological Surgery, School of Medicine, University of Tsukuba, Japan
}

SUMMARY A clinico-radiological analysis of 74 cases of ossification of the posterior longitudinal ligament is reported. Eighteen cases $(24 \%)$ were asymptomatic or only had neck or shoulder pain; 16 cases $(22 \%)$ showed signs of radiculopathy, and the remaining 40 cases $(54 \%)$ had myelopathy. Ossification of the posterior longitudinal ligament developed most frequently at C5, and was rare in thoracic and lumbar regions. Ossification of the posterior longitudinal ligament led to stenosis of the spinal canal; more marked stenosis caused clinical myelopathy. The data showed that $30 \%$ of stenosis caused by ossification of the posterior longitudinal ligament was critical for the production of myelopathy.

In 1960, Tsukimoto $^{1}$ reported the first case of the disease caused by ossification of the posterior longitudinal ligament, and later, in 1964, this was defined by Terayama ${ }^{2}$ as a clinical entity on the basis of histological findings.

The features of this disorder are as follows: $:^{3-12}(a)$ it is rare in Caucasians ${ }^{13-17}$ but is common in Asians, particularly the Japanese, $(b)$ it tends to develop in the cervical area and often is associated with spondylosis, $(c)$ it can be asymptomatic but usually is accompanied by either myelopathy or radiculopathy or by both, $(d)$ it is more common in males. ${ }^{18-21}$

In the present study the authors reviewed a total of 74 cases of ossification of the posterior longitudinal ligament and based their opinions on radiological findings correlating with the results of clinical analysis.

\section{Materials and methods}

The subjects were those diagnosed as having ossification of the posterior longitudinal ligament in Tsukuba University Hospital. It was our rule to perform at least tomography of the cervical vertebrae, and some of the subjects underwent CT scan with GE-CT/T8800. There were 46 males $(62 \%)$

Address for reprint requests: Dr T Nose, 1-1-1, Tennodai, Sakuramura. Niihari-gun. Ibaraki, Japan. 305.

Received 13 August 1985 and in revised form 5 March 1986. Accepted 8 March 1986. and 28 females $(38 \%)$. The ages ranged from 31 to 81 years, with the peak incidence occurring at age 64 .

Those without symptoms or neck/shoulder pain only numbered $18(24 \%)$; those with radiculopathy numbered 16 $(22 \%)$, and those showing myelopathy numbered 40 cases $(54 \%)$ (table 1$)$.

\section{Results}

\section{Distribution of ossification of the posterior}

longitudinal ligament in the whole spine (fig. 1)

In the majority of cases, the lesion was demonstrated exclusively in the cervical area. Two cases had additional lesions; one in the upper and one in the lower thoracic level. None had ossification of the posterior longitudinal ligament between $T h 1$ and Th11. Four cases showed lesion in the lumbar region, of which three cases had cervical lesion as well. Only one case out of 74 had a lesion restricted to the lumbar area. The distribution of ossification of the posterior longitudinal ligament in the cervical spine is shown in fig 1 , which demonstrates the localisation and extent of the lesions. In the figures the subjects were arranged in order of age, the left end being the youngest. The lesion tended to grow longitudinally, parallel with aging. The lesion was apt to occur in the posterior

Table 1 Classification of symptoms

Asymptomatic or neck/shoulder pain 


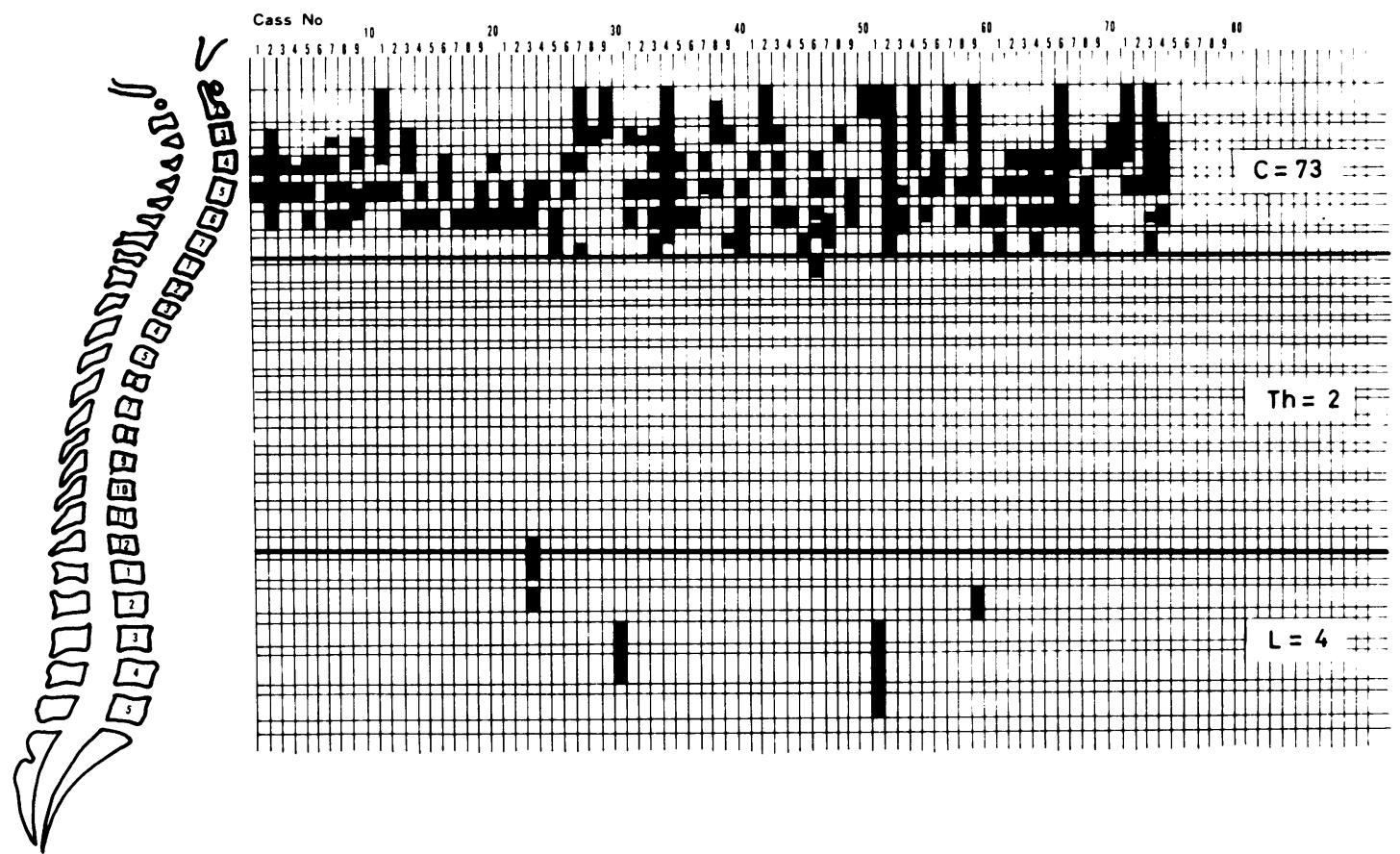

Fig 1 Distribution of ossification of the posterior longitudinal ligament in the whole spine.

area of the vertebrae and less frequently in between them. It was seen most frequently at the $\mathrm{C} 5$ level and decreased in number in the order of $\mathrm{C} 6, \mathrm{C} 4$ and $\mathrm{C} 3$.

Comparison of anteroposterior diameter of the spinal canal between normal control and ossification of the posterior longitudinal ligament patient (table 2)

The anteroposterior diameters of the spinal canal (D1 in table 3) of the patients with ossification of the posterior longitudinal ligament obtained from the lateral view of midline tomography were compared with that of normal adult Japanese. ${ }^{18}$ The anteroposterior diameters of the patients with ossification of the posterior longitudinal ligament were smaller than normal, especially at the level of C4 and C5 and less conspicuously at $\mathrm{C} 3$ and $\mathrm{C} 6$. This suggests that the ossification of the posterior longitudinal ligament was the basis for canal stenosis. The anteroposterior diameters of those with ossification of the posterior longitudinal ligament were compared with asymptomatic, radiculopathic and myelopathic groups at the level of C4, C5 and C6. On average, the anteroposterior diameters in the asymptomatic group were the widest, followed by those with radiculopathy and myelopathy.

Table 2 Comparison of anteroposterior diameter of spinal canal between normal control and asymptomatics and symptomatics in cases of ossification of the posterior longitudinal ligament

\begin{tabular}{|c|c|c|c|c|c|c|}
\hline & \multirow{2}{*}{$\begin{array}{l}\text { Normal n:30 } \\
\text { (Japanese) }\end{array}$} & \multicolumn{5}{|c|}{ Ossification of the posterior longitudinal ligament } \\
\hline & & Total cases ( $n$ ) & Asymptomatic & Radiculopathy & Myelopathy & \\
\hline $\mathrm{C} 2$ & $19 \cdot 7 \pm 2 \cdot 7$ & $19 \cdot 0 \pm 2 \cdot 3(12)$ & $20 \cdot 0$ & - & $21 \cdot 0$ & NS \\
\hline C 3 & $17 \cdot 4 \pm 2.3$ & $16.1 \pm 1.3(17)^{*}$ & 15.0 & $14 \cdot 0$ & 15.5 & NS \\
\hline $\mathrm{C} 4$ & $16.8 \pm 1.6$ & $15.4 \pm 1.7(28) \dagger$ & 17.0 & $16 \cdot 0$ & 14.5 & \pm \\
\hline C5 & $16.9 \pm 2.1$ & $15.8 \pm 1.8(39) \dagger$ & $17 \cdot 0$ & $17 \cdot 0$ & $15 \cdot 0$ & $\stackrel{\ddagger}{\ddagger}$ \\
\hline C6 & $17.7 \pm 1.5$ & $16.9 \pm 1.6(34)^{*}$ & 17.6 & 17.0 & 16.0 & 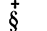 \\
\hline C7 & $16.7 \pm 1.6$ & $16.4 \pm 1 \cdot 1(8)$ & 17.0 & - & 14.0 & NS \\
\hline
\end{tabular}

${ }^{*} \mathrm{p}<0.05 ; \uparrow \mathrm{p}<0.025 ; \ddagger \mathrm{p}<0.01 ; \S \mathrm{p}<0.05$. 
Table 3 Comparison of rate of canal stenosis by OPLL between asymptomatics and symptomatics

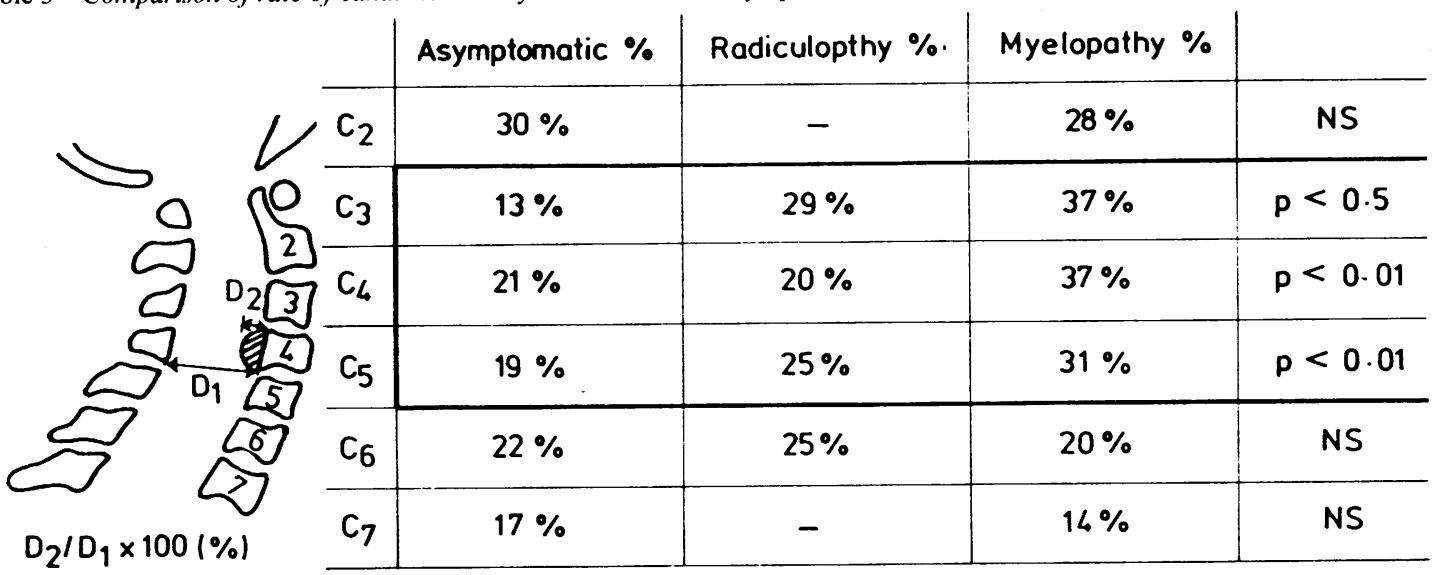

Comparison of degree of canal stenosis by ossification of the posterior longitudinal ligament between symptomatic and asymptomatic patients (table 3) The thickness of ossification of the posterior longitudinal ligament (D2) was divided by the anteroposterior diameter (D1) to determine the canal stenosis ratio $(\mathrm{D} 2 / \mathrm{D} 1 \times 100)$. The asymptomatic group showed a ratio of $20 \%$, radiculopathic groups ranged from $20 \%$ to $29 \%$, and the myelopathic group had a ratio of $30 \%$. These figures were significant at the levels of $\mathrm{C} 3, \mathrm{C} 4$ and $\mathrm{C5}$.

\section{Classification of ossification of the posterior} longitudinal ligament on the basis of radiological findings and the ratio of canal stenosis (fig 2, table 4) The ossification of the posterior longitudinal ligament was classified into four types after Nakanishi ${ }^{3}$ based on its configuration, namely hook type, staple type, bridge type and total type (fig 2). The numbers of each type were analysed in relation to the ratio of canal stenosis (table 4). Among them, the staple type was most frequently seen, followed by the bridge, the hook and lastly by total type. In the relation between types and the ratio of stenosis, the hook type showed a ratio of $15 \%$, the staple $20 \%$, the bridge $37 \%$, and the total type showed $45 \%$ stenosis on the average. Thus a good correlation was obtained between the configuration of ossification of the posterior longitudinal ligament and the degree of stenosis of the spinal canal.

Significance of computed tomography (CT) in diagnosis of ossification of the posterior longitudinal ligament (figs 3,4)

A CT scan was carried out in 24 out of 74 cases. Ossification of the posterior longitudinal ligament

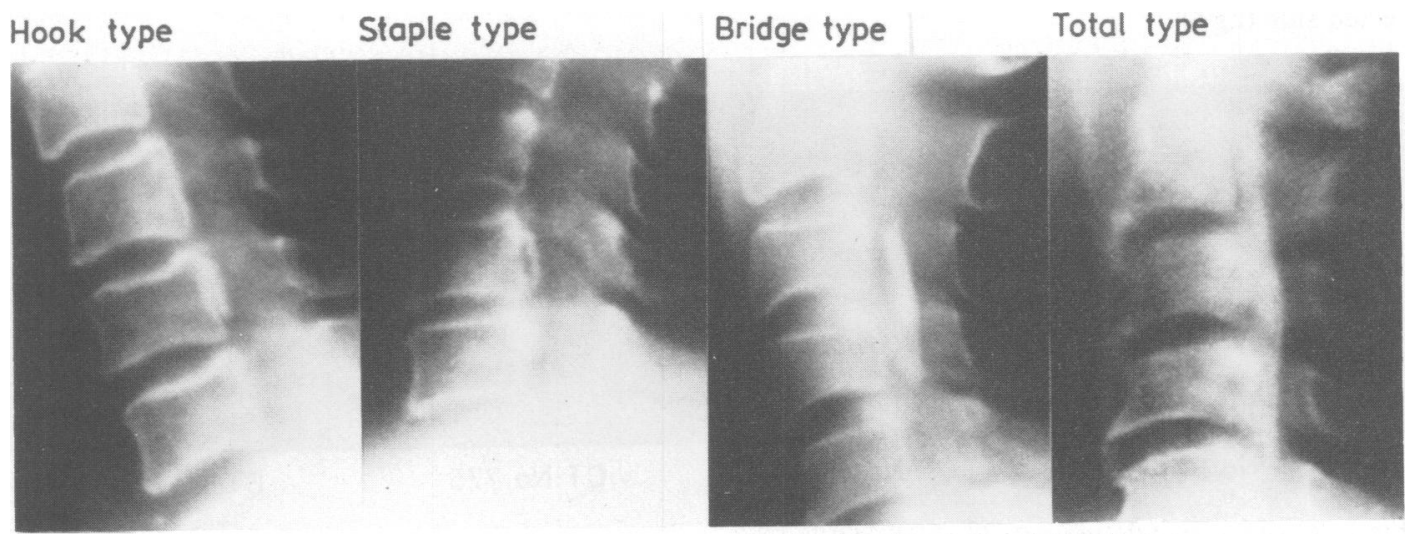

Fig 2 Classification of ossification of the posterior longitudinal ligament on the basis of radiological finding. 
Table 4 Classification of ossification on radiographs and rate of canal stenosis

\begin{tabular}{|c|c|c|c|}
\hline & & No & $D_{2} / D_{1} \times 100(\%)$ \\
\hline Type 1 & $\begin{array}{c}\text { Hook type } \\
\text { Holl }\end{array}$ & 10 & $15 \%$ \\
\hline Type II & Staple type & 97 & $24 \%$ \\
\hline Type III & Bridge type & 22 & $37 \%$ \\
\hline Type IV & $\begin{array}{c}\text { Total type } \\
\text { The }\end{array}$ & 7 & $45 \%$ \\
\hline & & 123 & $p<0.01$ \\
\hline
\end{tabular}

was demonstrated on the CT scan as a dense, abnormal shadow extending from the posterior surface of the vertebral body into the spinal canal. Its size varied from a small nodule to an almost rock-like sessile lesion (fig 3). The CT scan had an advantage in detecting the position of ossification of the posterior longitudinal ligament. The myelopathic group had a tendency for ossification of the posterior longitudinal ligament to occur near the midline of the posterior surface of the vertebra, while the radiculopathic group showed ossification of the posterior longitudinal ligament more eccentrically toward the affected side (fig 4).
Myelopathy:
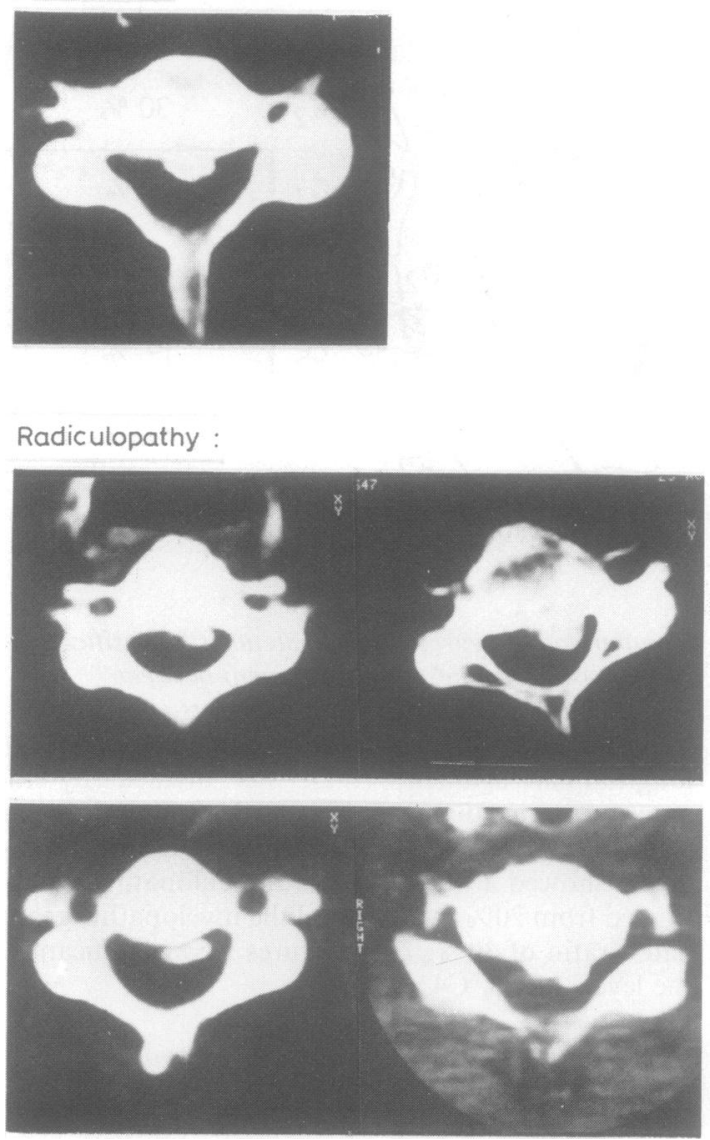

Fig 4 The CT scan had an advantage in detecting the position of ossification of the posterior longitudinal ligament. The myelopathic group had a tendency to have it near the midline of the spinal canal and the radiculopathic group showed more eccentrically toward the affected side.

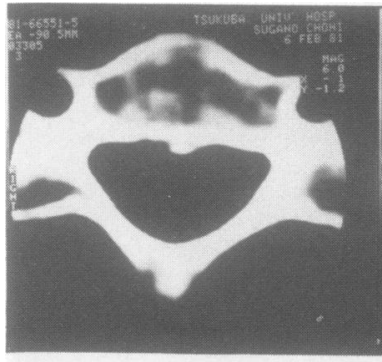

CT No 571

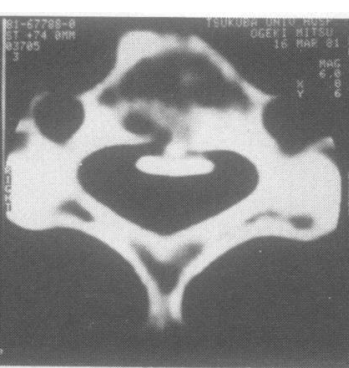

CT No 533

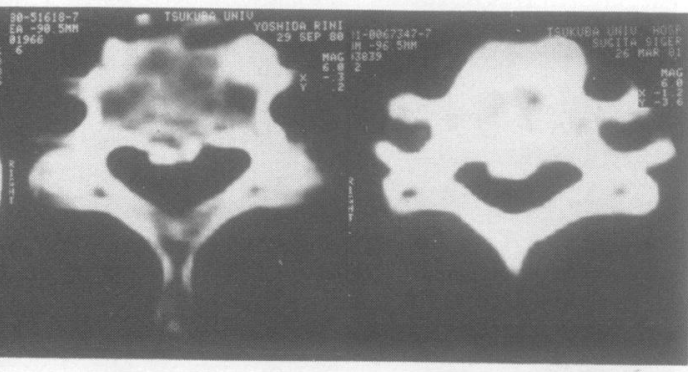

CT No 775
CT No 964

Fig 3 Ossification of the posterior longitudinal ligament is recognised on CT as a dense abnormal shadow extending from posterior surface of the vertebral body into spinal canal. 


\section{Discussion}

According to Terayama and Yamaura, ${ }^{20} 24$ this disease is distributed throughout southeast Asia and is frequently found in Japan. But factors other than ethnic differences must be taken into account because there are cases reported in Caucasians as well.

About $1.6 \%$ and $2 \cdot 2 \%$ of Japanese patients who complained of neck or lumbar pain were reported to show ossification of the posterior longitudinal ligament in radiographs. ${ }^{6}$ It develops more frequently after age 40 years. According to the majority of Japanese reports, ${ }^{3-7}$ the most affected levels are C4 and $\mathrm{C} 5$, although Okamoto ${ }^{19}$ stated that $\mathrm{C} 3$ and $\mathrm{C} 4$ were the most common levels. Osseous tissue was reported to be the essential finding of ossification of the posterior longitudinal ligament based on necropsy examination. ${ }^{20-22}$ According to these reports: $(a)$ this abnormal osseous tissue replaced the ligament itself, and the fibres of the ligament had clear continuity with the osseous tissue; $(b)$ the osseous tissue was interrupted at the intervertebral disc level where the ligament consisted of cartilage and chondrofibrous tissue with calcium deposits; $(c)$ the discs were atrophic and showed tears in some places. The trabeculae of the vertebral body were also atrophic; (d) inflammatory change or any other changes that might give rise to abnormal calcification have not been found so far.

Our speculation at present regarding the aetiology of ossification of the posterior longitudinal ligament is as follows. First, repetitive and trivial daily movements of the neck, together with aging, damage the intervertebral discs, and this in turn gives rise to damage of the posterior longitudinal ligament in the vicinity of the annulus fibrosus and/or at the attachment of the ligament to the vertebral body. The process of ossification begins along with the repairing of the damaged ligament. Abnormalities of glucose metabolism or sex hormones have been reported ${ }^{29}$ in some cases, but this is not enough to explain all the cases.

The intimate relation of ossification of the posterior longitudinal ligament and cervical spondylosis is well known. ${ }^{34}$ According to Satoh, ${ }^{23}$ the patient with ossification of the posterior longitudinal ligament usually has a narrow spinal canal as a basic abnormality, especially in those with symptoms. The present analysis also revealed a significant difference in the degree of stenosis between symptomatic and asymptomatic groups. The former showed severe stenosis on the average.

The reason for the combination of ossification of the posterior longitudinal ligament and spondylosis or narrow spinal canal is not known. Yet it is obvious that patients with spondlylosis or a narrow spinal canal tends to develop symptoms when they develop ossification of the posterior longitudinal ligament in addition.

Although there are some reports ${ }^{724}$ stating that the stenosis ratio of $40 \%$ is critical for the appearance of myelopathy, the authors believe their figure of $30 \%$ is sufficient. There have been some reports ${ }^{25-28}$ stressing the value of a CT scan in the diagnosis of ossification of the posterior longitudinal ligament. The ossification of the posterior longitudinal ligament can be nodular, rod shaped or sessile on a CT scan and its absorption coefficient ranges from 500 to 900 Hounsfield units according to our data. Thus a CT scan is very useful with regard to the extent and direction of the protruded ossification of the posterior longitudinal ligament, especially in the radiculopathic group where accurate localisation can be achieved.

As for the treatment, posterior decompression by laminectomy has been employed. Nagashima ${ }^{10}$ carried out laminectomy in 10 cases and reported that six obtained excellent improvement and three good benefit on follow-up. The remaining case could not be followed up. On the other hand, $\mathrm{Abe}^{30}$ recommends the anterior approach on the basis of his experience of recurrence of symptoms after laminectomy. However, because of post-operative stenosis due to scar formation, malalignment, and the postoperative increase of instability, laminoplasty is currently the favoured choice in Japan. ${ }^{31}$

\section{References}

1 Tsukimoto $H$. An autopsy case with spinal cord compression syndrome owing to ossification within spinal canal of cervical spine (in Japanese). J Jap Orthop Assoc 1960;34:107.

2 Terayama K, Maruyama S, Miyashita R. Ossification of the posterior longitudinal ligament of the cervical spine (in Japanese). Orthop Surg 1964;15:1081-95.

3 Nakanishi T, Toyokura Y, Mannen T, Sakaguchi R, Tsuyama N. Ossification of the posterior longitudinal ligament of the cervical spine, clinical findings and radiological features (in Japanese). Clin Neurol 1967;7:607-18.

4 Yanagi T, Yamamura T, Ando K, Sobue I. Ossification of the posterior longitudinal ligament of the cervical spine-Analysis of 37 cases (in Japanese). Clin Neurol 1967;7:727-35.

5 Shibasaki H, Nagamatsu K. Calcification of the posterior longitudinal ligament: its relation with cervical spondylosis (in Japanese). Clin Neurol 1968;7:22-9.

6 Yanagi T. Ossification of the posterior longitudinal ligament-a clinical and radiological analysis of 46 cases. Clin Neurol 1970;22:13-25.

7 Seki H, Tsuyama N, Hayashi K. Clinical evaluation of 185 patients with ossification of the posterior longitudinal ligament (in Japanese). Orthop Surg 1974; 25:704-10.

8 Onji Y, Akiyama H, Shinomura Y. Posterior para- 
vertebral ossification causing cervical myelopathy. $J$ Bone and Joint Surg A 1967;49:1314-28.

9 Hiramatsu Y, Nobechi T. Calcification of the posterior longitudinal ligament of the spine among Japanese. Diagnostic Radiology 1971;100:307-12.

10 Nagashima C. Cervical myelopathy due to ossification of the posterior longitudinal ligament. $J$ Neurosurg 1972;37:653-60.

11 Nakanishi T, Mannen T, Toyokura Y, Sakaguchi R, Tsuyama N. Symptomatic ossification of the posterior longitudinal ligament of the cervical spine. Neurology 1974;24:1139-43.

12 Hanai K, Adachi H, Ogasawara H. Axial transverse tomography of the cervical spine narrowed by ossification of the posterior longitudinal ligament. J Bone Joint Surg B 1977;59:481-4.

13 Baker L, Cares HL, Smith RJ. Ossification in the region of the posterior longitudinal ligament as a cause of cervical myelopathy. J Neurol Neurosurg Psychiatry 1970;33:263-8.

14 Rozario RA, Levin H, Stein BM. Cervical myelopathy and radiculopathy secondary to ossification of the posterior longitudinal ligament. Surg Neurol 1978;10:17-20.

15 Resnick D, Guerra J, Robinson CA. Association of diffuse idiopathic skeletal hyperostosis (DISH) and calcification and ossification of the posterior longitudinal ligament. Am J Roentogenol 1978; 131:1049-53.

16 Hanna $M$, Watt I. Posterior longitudinal ligament calcification of the cervical spine. $\mathrm{Br} J$ Radiology 1979;52:901-5.

17 Britton JA. Cervical myelopathy due to ossification of the posterior longitudinal ligament. J Neurol Neurosurg Psychiatry 1984;47:1355-61.

18 Kageyama N. Diagnosis of the cervical spondylosis (in Japanese). Brain Nerve Injury 1969;1:37-40.

19 Okamoto Y, Yasuma T. Ossification of the posterior longitudinal ligament of cervical spine with or without myelopathy. J Jap Orthop Assoc 1967;40:1349-60.

20 Yamaura I, Takayama $\mathbf{H}$. A pathological study of ossification of the posterior longitudinal ligament (in Japanese). J Jap Orthop Assoc 1966;40:688-90.

21 Furuya K, Yamaura I, Takayama H. Ossification of the posterior longitudinal ligament of the cervical spine: a necropsy case (in Japanese). J Jap Orthop Assoc 1968;42:1131-8.

22 Murakami N, Muroga T, Sobue I. Cervical myelopathy due to ossification of the posterior longitudinal ligament. A clinicopathological study. Arch Neurol 1978;35:33-8.

23 Sato S, Tsuru M, Yaa K. The antero-posterior diameter of the cervical spinal canal in the ossification of the posterior longitudinal ligament (in Japanese), Clin Neurosurg (Tokyo) 1977:5:511-7.

24 Terayama K, Mamiya N, Suzuki A. Ossification of the posterior longitudinal ligament of the cervical spine. Clinical symptoms, roentogenographic changes and treatment (in Japanese). Clin J Orthop 1972; 23:478-87.

25 Kadoya S, Nakamura T, Ohashi M, Hirose G, Tada A. Ossification of the posterior longitudinal ligamentComparative studies with computerized tomography (in Japanese). Clin Neurosurg (Tokyo) 1979;7:63-70.

26 Hayman RA, Merten CW, Liebeskind AL, Naidich JB, Stein HL. Computed tomography in ossification of the posterior longitudinal ligament. Neuroradiol 1977;13:227-8.

27 Yamamoto I, Kageyama N, Nakamura K, Takahashi T. Computed tomography in ossification of the posterior longitudinal ligament. Surg Neurol 1979;12:414-8.

28 Murakami J, Russell WJ, Hayabuchi N, Kimura S. Computed tomography of posterior longitudinal ligament ossification: Its appearance and diagnostic value with special reference to thoracic lesion. J Comput Assist Tomogr 1982;6:41-50.

29 Motegi M, Kojima K, Okada H, Fujita R. Ethiological analysis of the ossification of the posterior longitudinal ligament (in Japanese). Orthopedic Surgery, Nanko-do (Tokyo) 1982:91-106.

30 Abe $\mathrm{H}$, Ito $\mathrm{T}$, Iwasaki $\mathrm{Y}$, Nakagawa $\mathrm{T}$, Kitaoka $\mathrm{K}$, Tsuru M. Anterior decompression for ossification of the posterior longitudinal ligament of cervical spine (in Japanese). Neurol Med Clin (Tokyo) 1980:1183-96.

31 Tsuji H. Laminoplasty for patients with compressive myelopathy due to so-called spinal canal stenosis in cervical and thoracic regions. Spine 1982;7:28-34. 